\title{
CONGRESSOS DA ABEM - TEMÁRIO
}

Tendo em vista que se estabeleceu como tema central do XXXI Congresso a "Ética da Educação Médica" e considerando que a expressão ética é entendida como ato de reflexão crítica sobre valores, tornou-se oportuno (e até imperativo dentro desta compreensão do tema central) analisar os temas escolhidos nos 30 anos anteriores.

O simples enunciado dos temas dos 30 Congressos Brasileiros de Educação Médica da ABEM é suficientemente expressivo para demonstrar o pioneirismo da ABEM e a constante preocupação com diversos tópicos da educação médica no país. O $1^{\circ}$ Congresso teve como tema "Novos Rumos para o Ensino Médico", em 1963, o XXX "Desafios para a Educação Médica na passagem do milênio" e o último "Ética da Educação Médica".

Ao lado do temário, nestes 31 anos, pode-se constatar que a $\mathrm{ABEM}$ realizou os Congressos em vários Estados da Federação do norte ao sul do país.

São 31 anos de atividades em Educação Médica. De 1963 a 1974, os conclaves da ABEM se denominavam Reunião Anual; a partir de 1975 o encontro passou a se denominar Congresso Brasileiro de Educação Médica.

Como homenagem às diretrizes das gestões anteriores, aos organizadores dos encontros e a título de reflexão e demonstração de uma das atividades da $\mathrm{ABEM}$, é apresentada, a seguir, a relação dos temas de cada Congresso, bem como a data da realização e a sede.

\section{ABEM - CONGRESSOS}

\section{Reunião Anual}

\begin{tabular}{|c|c|}
\hline I - & $\begin{array}{l}\text { 1963: } \\
\text { (Recife) }\end{array}$ \\
\hline II - & $\begin{array}{l}\text { 1964: } \\
\text { (Poços de Caldas) }\end{array}$ \\
\hline III - & $\begin{array}{l}\text { 1965: } \\
\text { (Porto Alegre) }\end{array}$ \\
\hline IV - & $\begin{array}{l}\text { 1966: } \\
\text { (Salvador) }\end{array}$ \\
\hline V - & $\begin{array}{l}\text { 1967: } \\
\text { (C.Jordão) }\end{array}$ \\
\hline VI - & $\begin{array}{l}\text { 1968: } \\
\text { (Fortaleza) }\end{array}$ \\
\hline VII - & $\begin{array}{l}\text { 1969: } \\
\text { (Niterói) }\end{array}$ \\
\hline VIII - & $\begin{array}{l}\text { 1970: } \\
\text { (Brasilia) }\end{array}$ \\
\hline
\end{tabular}

- Novos Rumos para o Ensino Médico

- Pedagogia aplicada à Medicina

- Internato e Residência

- Formação de Pessoal Para-Médico

- Preparo e seleção de alunos

- Ensino da Psicologia no Curriculo Médico

- Atividades Extra-Curriculares dos Estudantes de Medicina

- Seminário sobre Administração de Escolas Médicas

- O Hospital de Ensino

- Preparo Pedagógico do Pessoal Docente em Medicina

- Integração do ensino das Ciências da Saúde

- O Ensino das Ciências Básicas nas Escolas Médicas e sua Integração na Formaçāo Profissional

- A Realidade Médico-Assistencial Brasileira

- O pessoal de saúde necessário

- Formação do médico de acordo com as diversidades das equipes de saúde

- A Educação Médica e o planejamento de Recursos Humanos para a saúde

- O processo de elaboração do plano de estudos

- A Avaliação Cientifica: Um instrumento indispensável para a tomada de decisões

- Planejamento estrutural e administrativo na formação de Recursos Humanos para a Saúde

- Relação Médico - Paciente

$\begin{array}{ll}\text { IX - } & \begin{array}{l}\text { 1971: } \\ \text { (Curitiba) }\end{array} \\ \text { X - } & \begin{array}{l}\text { 1972: } \\ \text { (João Pessoa) }\end{array} \\ \text { XI - } & \begin{array}{l}1973: \\ \text { (Rio de Janeiro) }\end{array} \\ \text { XII - } & \begin{array}{l}1974: \\ \text { (São Paulo) }\end{array} \\ \text { XIII - } \quad \begin{array}{l}1975: \\ \text { (Salvador) }\end{array}\end{array}$

- Expansão do Ensino Médico e a criação de novas escolas médicas no Brasil: problemas e soluçōes

- A Pós-Graduação no Ensino Médico

- A Pós-Graduação no Ensino Médico

- Ensino Médico e Previdência Social

- Internato

- O Ambulatório no Ensino Médico 


\begin{tabular}{|c|c|c|}
\hline & (Congresso Brasileiro) & $\begin{array}{l}\text { - Ciclo básico: comum ou diferenciado } \\
\text { - Residência Médica: análise e proposições }\end{array}$ \\
\hline XIV - & $\begin{array}{l}\text { 1976: } \\
\text { (Rio de Janeiro) }\end{array}$ & - Tendências atuais em Educação Médica \\
\hline $\mathbf{X V}-$ & $\begin{array}{l}\text { 1977: } \\
\text { (Belém) }\end{array}$ & $\begin{array}{l}\text { - Ensino das disciplinas básicas na área de Saúde, } \\
\text { face à Reforma Universitária } \\
\text { - Ensino de Clinica Médica } \\
\text { - Realidade da matrícula por disciplina nas escolas médicas }\end{array}$ \\
\hline XVI - & $\begin{array}{l}\text { 1978: } \\
\text { (Londrina) }\end{array}$ & $\begin{array}{l}\text { - O Médico de Familia } \\
\text { - Formação ética do médico }\end{array}$ \\
\hline XVII - & $\begin{array}{l}\text { 1979: } \\
\text { (P.Caldas) }\end{array}$ & $\begin{array}{l}\text { - Experiências com Novos Modelos de Formação Médica } \\
\text { - Experiências com Integração Docente-Assistencial }\end{array}$ \\
\hline XVIII - & $\begin{array}{l}\text { 1980: } \\
\text { (Goiânia) }\end{array}$ & $\begin{array}{l}\text { - Papel da Escola Médica diante da Prev.Saúde } \\
\text { - O Médico e o Mercado de Trabalho }\end{array}$ \\
\hline XIX - & $\begin{array}{l}\text { 1981: } \\
\text { (Recife) }\end{array}$ & $\begin{array}{l}\text { - Avaliação do rendimento escolar } \\
\text { - Internato } \\
\text { - Análise crítica da pós-graduação em Medicina } \\
\text { - Custos e financiamento dos Hospitais de Ensino }\end{array}$ \\
\hline $\mathbf{X X}-$ & $\begin{array}{l}\text { 1982: } \\
\text { (Ribeirão Preto) }\end{array}$ & - A qualidade da Educação Médica \\
\hline XXI - & $\begin{array}{l}\text { 1983: } \\
\text { (Fortaleza) }\end{array}$ & - Integração Ensino-Serviço \\
\hline XXII - & $\begin{array}{l}\text { 1984: } \\
\text { (Gramado) }\end{array}$ & $\begin{array}{l}\text { - Ética da Pesquisa Médica } \\
\text { - Ética da Remuneração Médica }\end{array}$ \\
\hline XXIII - & $\begin{array}{l}\text { 1985: } \\
\text { (Uberlândia) }\end{array}$ & - Formação de Recursos Humanos e o Sistema Nacional de Saúde \\
\hline XXIV - & $\begin{array}{l}\text { 1986: } \\
\text { (Florianópolis) }\end{array}$ & $\begin{array}{l}\text { - Prioridades na Educação Médica } \\
\text { - Estratégias educacionais para as Escolas Médicas } \\
\text { - Integração da Escola Médica com o Sistema de Atenção à Saúde }\end{array}$ \\
\hline XXV - & $\begin{array}{l}\text { 1987: } \\
\text { (Maceió) }\end{array}$ & $\begin{array}{l}\text { - O Momento Atual: A Educação Médica frente à Reforma Sanitária } \\
\text { - Perspectivas para a Reforma da Educação Médica: Uma visão prospectiva } \\
\text { da Educação Médica: A Conferência de Edimburgo }\end{array}$ \\
\hline XXVI - & $\begin{array}{l}\text { 1988: } \\
\text { (Rio de Janeiro) }\end{array}$ & - Reforma da Educação Médica \\
\hline XXVII - & $\begin{array}{l}\text { 1989: } \\
\text { (Manaus) }\end{array}$ & - A Reforma da Educação Médica exigida pela Constituição \\
\hline XXVIII - & $\begin{array}{l}\text { 1990: } \\
\text { (Cuiabá) }\end{array}$ & $\begin{array}{l}\text { - Pesquisa em Educação Médica } \\
\text { - O papel do Hospital de Ensino na Graduação em Medicina } \\
\text { - A incorporação tecnológica e a Medicina }\end{array}$ \\
\hline XXIX - & $\begin{array}{l}\text { 1991: } \\
\text { (Campinas) }\end{array}$ & $\begin{array}{l}\text { - Educação Médica e o exercicio profissional } \\
\text { - I Fórum de Avaliação do Ensino Médico }\end{array}$ \\
\hline XXX - & $\begin{array}{l}\text { 1992: } \\
\text { (Londrina) }\end{array}$ & $\begin{array}{l}\text { - Desafios para a Educação Médica na passagem do milênio } \\
\text { - II Fórum de Avaliação do Ensino Médico }\end{array}$ \\
\hline XXXI - & $\begin{array}{l}\text { 1993: } \\
\text { (São Luiz) }\end{array}$ & $\begin{array}{l}\text { - Ética da Educação Médica } \\
\text { - III Fórum de Avaliação do Ensino Médico }\end{array}$ \\
\hline
\end{tabular}

Prof. William Saad Hossne Presidente da ABEM e da CINAEM

Professor Titular de Cirurgia e Professor responsável pela Ética da Faculdade de Medicina de Botucatu - UNESP-SP. 